\title{
CUSTOMER RELATIONSHIP MANAGEMENT (CRM) DALAM DUNIA DIGITAL MELALUI SISTEM E-COMMERCE
}

\author{
Jam'an \\ Universitas Muhammadiyah Makassar \\ Email: andi.jam’an@unismuh.ac.id
}

\begin{abstract}
Abstrak
Kemajuan teknologi menyebabkan banyak sekali perubahan yang terjadi dalam berbagai kehidupan manusia, termasuk di antaranya kegiatan berbelanja. Melalui kehadiran internet, kegiatan berbelanja kini tidak lagi perlu dilakukan secara tradisional, melainkan dapat dilaksanakan dengan memanfaatkan e-commerce yang ada. Keberadaan e-commerce membuat berbagai perusahaan perlu menyesuaikan strategi bisnis Customer Relationship Management (CRM) milik mereka. Hal ini dikarenakan akan terdapat adanya banyak perubahan yang terjadi dalam CRM ketika berada di dalam lingkungan e-commerce. Penelitian ini dijalankan menggunakan pendekatan kualitatif dengan sumber data yang berasal dari penelitian-penelitian terdahulu. Hasil penelitian menunjukkan terdapat adanya perubahan yang terjadi dalam CRM ketika berada di lingkungan e-commerce. Kemudian penelitian ini juga menemukan bagaimana karakteristik CRM selama berada di lingkungan e-commerce.
\end{abstract}

Kata Kunci: Customer Relationship Management (CRM), E-commerce, Pelanggan, Perusahaan.

\begin{abstract}
Advances in technology have caused a lot of changes that occur in various human lives, including shopping activities. Through the presence of the internet, shopping activities now no longer need to be done traditionally, but can be carried out by utilizing existing e-commerce. The existence of e-commerce makes various companies need to adjust their Customer Relationship Management (CRM) business strategies. This is because there will be many changes that occur in CRM when they are in an e-commerce environment. This research was carried out using a qualitative approach with data sources derived from previous studies. The results show that there are changes that occur in CRM when in an e-commerce environment. Then this research also finds out how the characteristics of CRM while in the e-commerce environment.
\end{abstract}

Keywords: Customer Relationship Management (CRM), E-commerce, Customers, Companies.

\section{A. PENDAHULUAN}

Customer Relationship Management (CRM) merupakan suatu strategi bisnis yang berubah oleh perusahaan dan berawal dari fokus utama terhadap produk yang dimiliki oleh perusahaan, menjadi berfokus kepada kepuasan dan loyalitas yang dimiliki oleh pelanggan (Panjaitan, 2019). Perubahan ini disebabkan oleh adanya permintaan yang berasal dari pasar serta adanya pembaharuan dalam konsep manajemen, sehingga hal ini kemudian akan menyebabkan terjadinya peningkatan dalam kompetisi antara perusahaan dan meningkatkan mode bisnis manajemen (Visnjic et al., 2018).

Pada dasarnya, inti utama yang ingin disampaikan oleh CRM merupakan konsep pemasaran yang berpusat kepada pelanggan. Hal ini dapat dilakukan melalui adanya pemanfaatan teknologi yang canggih, sehingga kemudian interaksi yang terjadi di antara pihak 
perusahaan dan pelanggan dapat dikelola dengan baik (Wulandari \& Parameswara, 2020). Interaksi yang dilakukan ini kemudian dapat meningkatkan jumlah pelanggan, menjaga hubungan yang erat dengan pelanggan, meningkatkan loyalitas yang dimiliki oleh pelanggan, hingga dapat memberikan keuntungan atau profit yang maksimal (Habibillah, 2018).

CRM yang baik sangat bergantung kepada kemampuan teknologi informasi untuk dapat berjalan dengan baik. Adapun bentuk teknologi informasi yang dibutuhkan oleh CRM utamanya adalah Internet, platform e-commerce, teknologi multimedia, artificial intelligence, dan berbagai hal lainnya (Bagale et al., 2021). CRM memiliki tujuan untuk dapat memperpendek waktu siklus penjualan, mengurangi biaya penjualan, hingga meningkatkan kepuasan pelanggan, keuntungan dan loyalitas (Sinaga \& Sinuraya, 2019).

Pelaksanaan CRM dengan menggunakan internet tentunya akan berbeda dengan pelaksanaan CRM biasa melalui cara tradisional. Perlu adanya berbagai perubahan yang perlu diperhatikan agar kegiatan CRM dapat berjalan dengan baik. Selain itu, CRM dapat juga diintegrasikan dengan sistem-sistem lainnya untuk dapat mencapai hasil yang optimal (Komalasari \& Nurmasari, 2020). Melalui penjelasan di atas, maka peneliti ingin mempelajari mengenai bagaimana CRM dilaksanakan di dalam dunia digital melalui sistem e-commerce.

\section{B. TINJAUAN PUSTAKA}

\section{Customer Relationship Management (CRM)}

Konsep mengenai CRM sendiri bukanlah merupakan suatu hal yang baru dalam dunia manajemen bisnis. Namun melalui adanya perkembangan teknologi, terjadi adanya perubahan dalam CRM bagi perusahaan-perusahaan yang mengimplementasikannya (Muhtadi \& Darsono, 2018). Melalui kemunculan software yang membantu melakukan otomatisasi penjualan (SFA), CRM berubah fokusnya menjadi pemasaran yang sifatnya one-to-one. Software SFA melakukan otomatisasi terhadap berbagai tugas-tugas yang sifatnya rutin untuk dilakukan, seperti melakukan pelacakan terhadap kontak dan memperkirakan pelanggan (Olomu, 2019). Software SFA memiliki tujuan untuk dapat memberikan kesempatan kepada tenaga penjualan agar dapat lebih berkonsentrasi kepada penjualan dibandingkan tugas-tugas administrasi.

Pada dasarnya CRM merupakan bagian dari pemasaran yang berfokus kepada hubungan dengan pelanggan, sehingga tujuannya adalah upaya untuk dapat meningkatkan profitabilitas dalam jangka waktu yang panjang melalui perubahan dari yang awalnya pemasaran berbasiskan transaksi dengan penekanan untuk mendapatkan pelanggan baru, menjadi retensi pelanggan dengan melakukan manajemen hubungan pelanggan yang sifatnya efektif (Adithya, 2021).

Dapat dikatakan bahwa CRM merupakan suatu aplikasi yang sifatnya lebih kompleks dan canggih. CRM akan melakukan upaya penambangan atau pengambilan data yang dimiliki oleh seorang pelanggan melalui semua titik yang pernah di kontak oleh pelanggan tersebut, sehingga kemudian dapat menciptakan suatu pandangan yang sifatnya komprehensif dan tunggal. Melalui hal ini, diharapkan profil dari pelanggan tersebut dapat terungkap, sehingga kemudian kebiasaan mereka dalam membeli suatu barang dapat dilacak (Haryanto \& Rufai, 2018).

Teknologi yang digunakan untuk dapat melacak dan menganalisis perilaku milik pelanggan dapat membuat perusahaan mudah untuk melakukan identifikasi terhadap pelanggan terbaik, sehingga upaya pemasaran dapat difokuskan dan penghargaan dapat diberikan kepada pelanggan yang memiliki kecenderungan untuk melakukan pembelian (Komalasari et al., 2021). Memiliki pengalaman yang lebih baik mengenai pelanggan mereka memungkinkan perusahaan untuk dapat melakukan interaksi, merespons dan juga berkomunikasi secara lebih efektif agar dapat meningkatkan retensi secara signifikan (Endrawati \& Juliani, 2018). 
Inovasi yang dilakukan dalam bidang teknologi, lingkungan persaingan yang kompetitif, dan dunia internet merupakan beberapa faktor yang dapat membuat dilaksanakannya inisiatif one-to-one antara perusahaan dan pelanggan dapat terjadi (Lam \& Law, 2019). Hubungan one-to-one ini dapat dikembangkan oleh perusahaan untuk dapat menyesuaikan pengalaman berbelanja yang baik, melakukan prediksi terhadap pola pembelian belanja online yang lebih baik, penarikan pelanggan melalui penawaran atau layanan khusus, melaksanakan evaluasi terhadap keuntungan ekonomi setiap pelanggan, hingga menciptakan hubungan jangka panjang yang sifatnya akan saling menguntungkan (Courchesne et al., 2019).

\section{E-Commerce}

Perkembangan yang sangat cepat dalam dunia e-commerce menciptakan berbagai masalah baru bagi para perusahaan yang mencoba mengembangkan strategi e-commerce. Hal ini sulit untuk dilakukan karena sifat dari aliran dalam teknologi informasi dan perangkat lunak berjalan terus-menerus tanpa terputus (Cahyono, 2018). Namun ketakutan terbesar bagi para perusahaan dalam melaksanakan strategi promosi e-commerce adalah hilangnya para pelanggan sebagai akibat dari para kompetitor yang dapat mengaplikasikan strategi ecommerce milik mereka sendiri yang sifatnya lebih baik (Abdiansyah, 2021).

Sejak kemunculannya, e-commerce telah menarik banyak sekali perhatian di kalangan ilmuwan dan peneliti. Hal ini kemudian menyebabkan tidak adanya batasan dalam definisi di antara para ilmuwan, peneliti ataupun berbagai penulis lainnya. Oleh karena itu, dalam penelitian ini akan diberikan gambaran singkat mengenai definisi konsep e-commerce (Zhou et al., 2021). Roger Clark berpendapat bahwa e-commerce merupakan suatu kegiatan juallbeli barang atau jasa yang dilakukan melalui alat telekomunikasi. Sementara itu, Jerry Ellison berpendapat bahwa e-commerce merupakan kontrak elektronik yang digunakan untuk melaksanakan pertukaran nilai, baik dalam bentuk barang, jasa atau bentuk-bentuk lainnya melalui teknologi informasi dan komunikasi (Kethineni et al., 2018).

Kemudian Anil Khural memberikan definisi kepada e-commerce sebagai penggunaan teknologi internet, komputer dan perangkat lunak untuk dapat melakukan pengiriman dan penerimaan spesifikasi dan gambar produk, pesanan dan pembelian, hingga berbagai jenis data lainnya yang perlu diteruskan kepada para pelanggan, pemasok, karyawan ataupun kepada publik (Babenko et al., 2019). E-commerce juga dapat didefinisikan sebagai kegiatan bisnis online berupa penjualan barang dan jasa yang kemudian dikirimkan secara offline. Hal ini juga berlaku bagi produk yang dapat didigitalkan sehingga dapat dikirimkan secara online, seperti contohnya adalah penjualan perangkat lunak.

Melalui berbagai definisi dari para ahli di atas, maka dapat disimpulkan definisi dari ecommerce berupa:

a. Dalam pengertian yang sempit, e-commerce merupakan transaksi keuangan yang dilakukan melalui jaringan internet atau komunikasi pribadi, di mana terjadinya pembelian atau penjualan barang dan jasa, serta dilaksanakannya transfer uang. Terjadinya transaksi dalam perdagangan elektronik membuktikan bahwa terdapat adanya keinginan dan juga kemungkinan bahwa memungkinkan untuk melakukan pembelian melalui kartu kredit serta terjadinya perpindahan uang yang dilakukan melalui transfer di antara satu akun ke akun lainnya (Chen \& Sivakumar, 2021).

b. Sementara itu, dalam pengertian yang luas e-commerce dapat didefinisikan sebagai semua hubungan bisnis yang terjadi di antara para aktornya melalui adanya penggunaan teknologi internet (Zaelani, 2019).

Berdasarkan pihak-pihak yang terjadi di dalam hubungan ekonomi dan interaksinya satu sama lain, teori mengenai e-commerce dapat dibedakan menjadi beberapa bagian. Adapun yang paling umum di antara bagian-bagian tersebut adalah: 
a. Business-to-Business (B2B)

Merupakan kegiatan yang dilakukan oleh perusahaan dalam menyediakan perusahaan manufaktur lain dengan layanan yang ikut menyertainya, serta berbagai barang dan jasa yang berfungsi untuk produksi barang-barang lainnya. Kegiatan ini dilakukan untuk mendapatkan manfaat atau keuntungan dari penyediaan jasa atau penjualan barang, di mana dalam hal ini objek merupakan barang atau jasa yang diperjualbelikan, sementara subyek merupakan organisasi yang melakukan interaksi dalam bidang pasar. Organisasi atau pengusaha perorangan akan bertindak sebagai penjual atau pembeli jasa atau barang dalam kegiatan ini (Rapaccini et al., 2020).

b. Business-to-Consumer (B2C)

Merupakan hubungan komersial yang terjadi di antara perusahaan dengan individu pribadi, yang juga sering disebut sebagai end consumer. Bentuk ini juga merupakan perdagangan elektronik yang dilakukan dengan tujuan penjualan langsung kepada para konsumen individu atau end consumer ini (Crittenden et al., 2019).

c. Consumer-to-Consumer (C2C)

Merupakan hubungan e-commerce yang terjadi di antara konsumen akhir dengan konsumen akhir. Dalam hubungan ini, pembeli dan penjual bukanlah merupakan suatu pengusaha ataupun perusahaan dalam pengertian umum. Dalam hubungan ini sering kali terdapat adanya pihak ketiga yang ikut terlibat dalam hubungan komersial ini. Pihak ketiga ini menjadi perantara, seperti penyelenggara platform perdagangan, seperti lelang online, ataupun situs dan perangkat lunak penjualan. Perantara pihak ketiga ini juga dapat menjadi penjamin atau pelaksana pembayaran. Walaupun bukan penjamin dari penerimaan barang, namun dalam beberapa kasus besar atau khusus, perantara dapat menjadi penyelesai dalam permasalahan yang kontroversial. Terakhir, pihak ketiga ini tidak ikut berpartisipasi dalam melakukan promosi terhadap barang yang di jual, namun hal ini dilakukan secara mandiri oleh penjual (Yuan et al., 2021).

d. Business-to-Government (B2G)

Merupakan hubungan yang terjadi di antara pelaku bisnis berupa pengusaha atau perusahaan dengan pemerintah. Dalam kerangka terjadinya proses globalisasi, sistem B2G yang dapat berfungsi sebagai sistem pengadaan elektronik yang terjadi di negara Ukraina (Chang et al., 2020).

e. Consumer-to-Government $(\mathrm{C} 2 \mathrm{G})$

Merupakan hubungan yang terjadi di antara konsumen individu dan negara untuk dapat mengatur interaksi langsung yang terjadi di antara keduanya. Contoh dari hubungan ini adalah adanya kewajiban dari negara untuk dapat mengajukan pendapatan yang dimiliki melalui situs departemen perpajakan (Christensen et al., 2020).

f. Mobile Commerce (m-commerce)

Merupakan proses yang terjadi dengan menggunakan komputer atau smartphone yang terhubung melalui jaringan internet jarak jauh. M-commerce dapat menjadi suatu solusi untuk melakukan otomatisasi proses interaksi jarak jauh dalam bentuk perangkat lunak ataupun perangkat keras (Bello \& Zeadally, 2019).

\section{METODE}

Penelitian ini dilaksanakan dengan menggunakan pendekatan kualitatif. Data yang digunakan dalam penelitian ini merupakan data sekunder yang diperoleh dari berbagai penelitian-penelitian terdahulu dan studi literatur yang masih berhubungan dengan CRM yang terjadi di dalam lingkungan e-commerce. Setelah data berhasil dikumpulkan, maka berikutnya data akan dianalisis, sehingga kemudian dapat diambil kesimpulannya. 


\section{HASIL DAN PEMBAHASAN \\ 1. Perubahan Customer Relationship Management (CRM) dalam Lingkungan E- Commerce}

Melalui kemunculan dari e-commerce, fokus yang dimiliki oleh berbagai perusahaan tradisional telah berubah, dari yang awalnya peningkatan efisiensi internal, berubah menjadi penghormatan pelanggan eksternal, serta mengintegrasikan sumber daya milik mereka, yang awalnya mode manajemen yang berfokus kepada internal, menjadi mode manajemen customer relationship yang berorientasi ke luar perusahaan. Selain memberikan cara komunikasi baru bagi para perusahaan dan pelanggan, e-commerce juga akan memberikan suatu sistem persyaratan baru terhadap CRM. Sistem CRM yang canggih dan efektif memerlukan adanya alat dan platform internet untuk dapat merealisasikan sinkronasi dan akurasi yang terjadi dalam berbagai hubungan pelanggan.

a. Transmisi informasi dengan sifat real-time dan tersinkronisasi

Lingkungan e-commerce akan mendukung terjadinya efektivitas bagi pelanggan untuk dapat mengakses informasi yang dimiliki oleh perusahaan setiap saat secara akurat. Agar departemen yang berfokus kepada pelanggan dapat berkoordinasi secara bebas dan sistem yang ada dapat berjalan secara sinkron, maka sistem CRM akan efektivitas sangat penting bagi interaksi pelanggan yang bersifat lengkap dan real-time dalam berbagi informasi agar sifatnya sinkron. Sistem CRM yang berhasil harus dapat memperhatikan sinkronisasi dari data dan informasi pelanggan untuk dapat memastikan bahwa setiap komunikasi yang dilakukan dengan para pelanggan dapat terjadi secara real-time dan tersinkronisasikan dengan menggunakan aplikasi teknologi berbasis jaringan.

b. Integrasi saluran komunikasi

Dalam era e-commerce, koordinasi berbasiskan e-commerce dan CRM menjadi semakin penting. Perusahaan perlu menganggap e-channel dan e-commerce sebagai bagian dari strategi CRM, serta harus dapat mengkoordinasikan hasil wawancara, email, telepon, faks, surat, dan akses web sehingga menjadi satu agar dapat memberikan konsistensi informasi yang diperoleh oleh semua saluran yang ada, menghindari terjadinya konflik antar saluran, hingga memungkinkan perusahaan untuk dapat memilih saluran yang terbaik untuk melakukan komunikasi dengan para pelanggan mereka agar dapat sesuai dengan preferensi yang disukai oleh mereka. Setelah pelaksaan integrasi saluran komunikasi, sistem CRM harus dapat memasukkan semua titik kontak pelanggan agar komunikasi yang terjadi di antara pelanggan dan perusahaan menjadi lancar, koheren dan efisien. Hal ini dilakukan agar sistem CRM dapat memberikan antarmuka e-commerce serta melakukan pendukungan dan pengembangan penuh terhadap e-commerce.

c. Dukungan terhadap operasi lintas platform

Sistem CRM yang berbasiskan kepada e-commerce tidak lagi terkonsentrasi dengan satu server LAN yang sama. Hal ini menyebabkan perlu adanya dukungan terhadap distribusi database dan aplikasi, serta dapat berjalan di berbagai platform dan sistem operasi yang berbeda. Hal ini dilakukan agar perusahaan dapat memilih platform yang terbaik bagi kebutuhan bisnis dan kemampuan investasi mereka, serta dapat membantu perusahaan untuk melakukan transisi yang sifatnya lancar dari berbagai macam tingkatan dan tahapan aplikasi. Hal ini menunjukkan bahwa operasi lintas platform memiliki sifat yang sangat penting.

d. Integrasi dengan sistem yang telah ada

Dalam lingkungan e-commerce. Operasi bisnis yang sifatnya konsisten dapat dilakukan dengan melalui pembangunan solusi CRM yang sifatnya terintegrasi untuk dapat mengkoordinasikan antara sistem aplikasi yang berada di latar belakang dengan latar 
depan dan strategi dari e-commerce. Namun terdapat adanya kesulitan yang terjadi ketika melakukan integrasi yang lancar di antara sistem CRM dan sistem perusahaan yang telah ada sebelumnya. Hal ini kemudian akan menyebabkan terjadinya data yang tidak saling berbagai antara sistem informasi dan terjadinya inkonsistensi data pelanggan yang dimiliki oleh departemen dengan sistem yang berbeda-beda. Hal ini pada akhirnya akan menyebabkan tidak meningkatnya kepuasan yang dimiliki oleh pelanggan, sulitnya menyediakan produk yang sesuai, serta waktu respons yang sulit untuk dapat dipersingkat.

\section{Karakteristik CRM di Dalam Lingkungan E-commerce}

Karakteristik CRM di dalam lingkungan e-commerce adalah sebagai berikut:

a. Personalisasi terhadap layanan dan dukungan pelanggan

Hanya melalui satu ketukan di mouse atau panggilan telepon saja, seorang pelanggan dapat beralih menuju ke perusahaan pesaing dalam lingkungan e-commerce. Hal ini dikarenakan pelanggan akan sangat bergantung kepada ketersediaan pelayanan dan dukungan terhadap pelanggan yang memiliki kualitas yang lebih baik. Melalui sistem CRM, perusahaan dapat memiliki alat yang berfungsi sebagai garda depan yang berorientasi terhadap pelanggan dengan fokus pada kecepatan, akurasi, efisiensi dan juga kebutuhan pelanggan yang sifatnya telah dipersonalisasi. Alat ini diharuskan untuk dapat memberikan solusi teknis yang sifatnya telah dipersonalisasi, layanan di tempat, pemeliharaan terhadap produk dan berbagai dukungan serta layanan lainnya yang diberikan kepada pelanggan secara otomatis dengan cara melakukan optimalisasi terhadap alur kerja mereka.

b. Interaktivitas

CRM dapat menciptakan komunikasi dua arah yang terjadi secara real-time di lingkungan e-commerce. Melalui adanya interaktivitas dan panduan internet yang baik, maka pelanggan akan dapat memilih produk atau layanan dan mengajukan persyaratan khusus melalui internet di bawah panduan sistem. Perusahaan kemudian dapat memproduksi dan memberikan layanan yang dipilih dan dibutuhkan oleh pelanggan dengan tepat waktu. Gabungan dari berbagai hal ini kemudian akan menciptakan komunikasi dua arah antara perusahaan dan pelanggan secara real-time. Melalui komunikasi ini, maka perusahaan dapat memberikan pelayanan yang lebih memuaskan bagi para pelanggannya.

c. Pemrosesan informasi cerdas dan fungsi pendukung pengambilan keputusan

Banyaknya informasi yang berada di dalam lingkungan e-commerce akan menyulitkan kemampuan manusia dalam memproses informasi tersebut. Oleh karena itu, keberadaan fungsi pemrosesan cerdas harus masuk ke dalam sistem CRM, seperti fungsi analisis data cerdas, fungsi pendukung keputusan cerdas, dan hal lainnya. Melalui pengambilan kepribadian pelanggan secara sepenuhnya, maka keuntungan yang dapat dihasilkan melalui pelanggan dapat terus ditemukan dan diperluas, sehingga kemudian fungsi sistem CRM tidak hanya sebatas kepada otomatisasi proses saja, namun juga sebagai alat analisis fungsi pendukung keputusan yang sifatnya cerdas agar dapat membantu pihak manajer dalam membuat keputusan.

d. Keamanan dan skalabilitas

Sebagai akibat dari banyaknya perubahan dan keberagaman bagi persyaratan pengguna, maka sistem aplikasi mana pun tidak dapat mencakup semua kebutuhan bagi semua pengguna. Oleh karenanya, sistem CRM yang berbasiskan e-commerce haruslah memiliki kerangka kerja yang mudah untuk diperluas dan dibuka, memiliki antarmuka eksternal yang sifatnya standar, dapat dihubungkan dengan sistem lainnya, atau dapat dipersonalisasi dan ditingkatkan sesuai dengan kebutuhan. Di saat yang sama, 
karakteristik keterbukaan, berbagi dan internet global membuat jangkauan dari pengaruh e-commerce akan menjadi semakin besar, sehingga sistem CRM yang berdasarkan e-commerce haruslah memiliki reliabilitas dan keamanan yang tinggi.

e. Pembagian data yang sifatnya terpadu

Dalam lingkungan e-commerce, seluruh data solusi CRM harus disimpan dan dikelola di suatu pusat agar dapat menciptakan pertukaran data dan integrasi dengan sistem aslinya. Semua jenis data yang berada di dalam sistem harus ditransfer ke dalam modul fungsional yang sifatnya relevan sesuai dengan peraturan internal dan yang telah ditetapkan sebelumnya serta hubungan manajemen pekerjaan, sehingga kemudian dapat mencapai pembagian data dan integrasi sistem yang tinggi.

f. Biaya operasi yang rendah

Salah satu keuntungan terpenting yang dimiliki oleh e-commerce adalah berkurangnya biaya operasional CRM sebagai akibat dari kehadiran internet. Dalam lingkungan ecommerce, setiap organisasi ataupun individu dapat mencari informasi yang mereka butuh kan melalui internet dengan biaya yang cukup murah. Hal ini kemudian memberikan manfaat yang besar bagi perusahaan dan pelanggan, sehingga kemudian menyebabkan terdorongnya orang-orang untuk mengumpulkan informasi dan melakukan komunikasi secara aktif. Sistem CRM bukan hanya pilihan yang sifatnya aktif bagi perusahaan, namun juga menjadi kebutuhan yang tidak dapat dihindari bagi sebagian besar pelanggan online.

g. Dukungan fungsional berbasiskan web

Web bukan hanya saluran yang sangat diperlukan dalam melaksanakan e-commerce, namun juga penting fungsinya dalam infrastruktur. Melalui CRM, maka perusahaan dapat melayani pelanggan secara real time melalui web, mewujudkan layanan mandiri dan berbagai hal lainnya. Hal ini akan memperluas saluran pemasaran dan layanan tradisional sehingga kemudian perusahaan dapat menyediakan layanan global tanpa adanya gangguan dan memaksimalkan peluang untuk mendapatkan keuntungan bagi perusahaan.

\section{E. KESIMPULAN}

Keberadaan CRM dalam dunia e-commerce memiliki banyak perbedaan dibandingkan CRM pada masa tradisional. Perubahan ini menyebabkan terjadinya transmisi informasi yang terjadi secara langsung, terjadinya integrasi dalam saluran komunikasi, adanya dukungan terhadap operasi lintas platform, hingga integrasi dengan sistem yang telah ada sebelumnya. Adapun karakteristik CRM yang berada di dalam lingkungan e-commerce adalah adanya personalisasi terhadap layanan dan dukungan pelanggan, adanya interaktivitas, adanya pemrosesan informasi cerdas, keberadaan skalabilitas dan keamanan, pembagian data yang dilakukan dengan terpadu, biaya operasional yang jauh lebih murah, hingga dukungan fungsional yang berbasiskan web.

\section{REFERENSI}

Abdiansyah, T. (2021). Inovasi Transaksi Ekonomi Berbasis Digital di Pasar Tradisional Probolinggo. Jurnal Sosial Politik Integratif, 1(3), 1-9.

Adithya, A. R. H. (2021). Sistem Informasi E-CRM Berbasis Web Untuk Peningkatan Loyalitas Serta Pelayanan. Jurnal Portal Data, 1(2).

Babenko, V., Kulczyk, Z., Perevosova, I., Syniavska, O., \& Davydova, O. (2019). Factors of the development of international e-commerce under the conditions of globalization. In SHS Web of Conferences (Vol. 65, p. 04016). EDP Sciences. 
Bagale, G. S., Vandadi, V. R., Singh, D., Sharma, D. K., Garlapati, D. V. K., Bommisetti, R. K., ... \& Sengan, S. (2021). Small and medium-sized enterprises' contribution in digital technology. Annals of Operations Research, 1-24.

Bello, O., \& Zeadally, S. (2019). Toward efficient smartification of the Internet of Things (IoT) services. Future Generation Computer Systems, 92, 663-673.

Cahyono, G. H. (2018). Kewirausahaan dan Inovasi dalam E-Commerce. Swara Patra, 8(1), 80-92.

Chang, Y., Iakovou, E., \& Shi, W. (2020). Blockchain in global supply chains and cross border trade: a critical synthesis of the state-of-the-art, challenges and opportunities. International Journal of Production Research, 58(7), 2082-2099.

Chen, Y., \& Sivakumar, V. (2021). Investigation of finance industry on risk awareness model and digital economic growth. Annals of Operations Research, 1-22.

Christensen, J., Aarøe, L., Baekgaard, M., Herd, P., \& Moynihan, D. P. (2020). Human capital and administrative burden: the role of cognitive resources in citizen-state interactions. Public Administration Review, 80(1), 127-136.

Courchesne, A., Ravanas, P., \& Pulido, C. (2019). Using Technology to Optimize Customer Relationship Management: The Case of Cirque du Soleil. International Journal of Arts Management, 21(2).

Crittenden, A. B., Crittenden, V. L., \& Crittenden, W. F. (2019). The digitalization triumvirate: How incumbents survive. Business Horizons, 62(2), 259-266.

Endrawati, D., \& Juliani, R. D. (2018). Hubungan Kualitas Layanan dengan Kepuasan Pelanggan PT. Indoguna Utama Semarang. Majalah Ilmiah Inspiratif, 3(6).

Habibillah, M. W. (2018). Pengaruh CRM Terhadap Kepercayaan Konsumen serta Dampaknya Terhadap Loyalitas Pelanggan Survey pada Petani Desa Donowarih, Kecamatan Karangploso, Kabupaten Malang. Cakrawala: Jurnal Litbang Kebijakan, 12(1), 25-39.

Haryanto, H., \& Rufai, A. (2018, November). Model Manajemen Hubungan Pelanggan dan Sistem Bisnis Intelijen untuk Katalog Secara Online. In Prosiding Seminar Nasional Rekayasa Teknologi Informasi| SNARTISI (Vol. 1).

Kethineni, S., Cao, Y., \& Dodge, C. (2018). Use of bitcoin in darknet markets: Examining facilitative factors on bitcoin-related crimes. American Journal of Criminal Justice, 43(2), 141-157.

Komalasari, D., Pebrianggara, A., \& Oetarjo, M. (2021). Buku Ajar Digital Marketing. Umsida Press.

Komalasari, E., \& Nurmasari, N. (2020). Analisis Pelaksanaan Customer Relationship Management Pada Usaha Kecil dan Menengah di Kota Pekanbaru. VALUTA, 6(1), 1731.

Lam, C., \& Law, R. (2019). Readiness of upscale and luxury-branded hotels for digital transformation. International Journal of Hospitality Management, 79, 60-69.

Muhtadi, A. S., \& Darsono, D. (2018). Strategi Indosat Mempertahankan Pelanggan melalui Customer Relationship Management. Reputation: Jurnal Hubungan Masyarakat, 1(2), 70-88.

Olomu, M. O. (2019). Marketing automation innovation practices and customer retention performance: evidence from the Nigerian manufacturing SMEs. International Journal of Business Performance Management, 20(3), 212-228.

Panjaitan, R. (2019). Analisis Penerapan E-Business Studi Kasus Pada Bank Tabungan Pensiunan Nasional (BTPN), Tbk. E-Bisnis: Jurnal Ilmiah Ekonomi dan Bisnis, 12(1), $1-12$. 
Rapaccini, M., Saccani, N., Kowalkowski, C., Paiola, M., \& Adrodegari, F. (2020). Navigating disruptive crises through service-led growth: The impact of COVID-19 on Italian manufacturing firms. Industrial Marketing Management, 88, 225-237.

Sinaga, A., \& Sinuraya, C. (2019). Perancangan Balanced Scorecard sebagai sistem manajemen strategik dalam pencapaian sasaran strategik jangka panjang (studi kasus pada PTPN XIII Persero Pontianak). Jurnal Ekonomi, 34-38.

Visnjic, I., Neely, A., \& Jovanovic, M. (2018). The path to outcome delivery: Interplay of service market strategy and open business models. Technovation, 72, 46-59.

Wulandari, I. G. A. A., \& Parameswara, A. A. G. A. (2020). Problematika UMKM Berbasis Budaya Lokal di Bali (Studi Kasus Pemasaran Produk UMKM Berbasis Budaya Lokal di Pesta Kesenian Bali). Ekonomi dan Bisnis, 6(2), 101-120.

Yuan, C., Moon, H., Wang, S., Yu, X., \& Kim, K. H. (2021). Study on the influencing of B2B parasocial relationship on repeat purchase intention in the online purchasing environment: An empirical study of B2B E-commerce platform. Industrial Marketing Management, 92, 101-110.

Zaelani, I. R. (2019). Peningkatan Daya Saing UMKM Indonesia: Tantangan dan Peluang Pengembangan Iptek. Jurnal Transborders, 3(1), 15.

Zhou, L., Zhang, L., Zhao, Y., Zheng, R., \& Song, K. (2021). A scientometric review of blockchain research. Information Systems and e-Business Management, 19(3), 757787. 